\title{
Cartografía social como recurso metodológico para el análisis patrimonial. Experiencias de mapeo en Miramar (Córdoba, Argentina $)^{1}$
}

\section{SOCIAL CARTOGRAPHY AS A METHODOLOGICAL RESOURCE FOR HERITAGE ANALYSIS. MAPPING EXPERIENCES IN MIRAMAR (CÓRDOBA, ARGENTINA)}

\author{
MAPEAMENTO SOCIAL COMO RECURSO METODOLÓGICO PARA A \\ ANÁLISE DO PATRIMÔNIO. EXPERIÊNCIAS DE MAPEAMENTO EM \\ MIRAMAR (CÓRDOBA, ARGENTINA)
}

Para citar este artículo: Martin Silva, V. B., Zabala, M. E. y Fabra, M. (2019). Cartografía social como recurso metodológico para el análisis patrimonial. Experiencias de mapeo en Miramar (Córdoba, Argentina). Perspectiva Geográfica, 24(2), 127-150. doi: 10.19053/01233769.8631

Valeria Belén Martin Silva ${ }^{2}$ Mariela Eleonora Zabala ${ }^{3}$ Mariana Fabra ${ }^{4}$

\section{Recepción:}

15 de noviembre de 2018

Evaluación:

8 de julio de 2019

\section{Aprobación:}

20 de agosto de 2019

1 Esta investigación fue posible gracias a una beca del Programa de Movilidad Académica entre todas las instituciones asociadas a la Asociación Universitaria Iberoamericana de Postgrado (AUIP), para desarrollar una estancia de investigación en el Museo de Antropología de la Facultad de Filosofía y Humanidades (UNC-Córdoba, Argentina) con el Programa de Arqueología Pública (PAP): diálogos posibles entre comunidades -locales, científicas, originarias- sobre restos humanos arqueológicos para su recuperación, conservación, investigación y gestión -Noreste provincia de Córdoba- (Res. HCD. 384/2017), bajo la dirección de las Dras. Mariana Fabra y Mariela Zabala. La estancia fue desarrollada entre los meses de febrero y junio de 2017.

2 Candidata a doctora en Patrimonio (Universidad de Huelva) y magíster en Estudios Americanos (Universidad de Sevilla).valeriabelen.silva@alu.uhu.es

3 Doctora en Ciencias Antropológicas (Universidad Nacional de Córdoba), Instituto de Antropología de Córdoba-Conicet, Museo de Antropología, magíster en Antropología (Facultad de Filosofía y Humanidades, Universidad Nacional de Córdoba), y licenciada y profesora en Historia (Facultad de Filosofía y Humanidades, Universidad Nacional de Córdoba). marielaeleonora@gmail.com

4 Doctora en Historia de la Universidad Nacional de Córdoba (UNC), Instituto de Antropología de Córdoba-Conicet, Museo de Antropología, Facultad de Filosofía y Humanidades (FFyH), magíster en Antropología (Facultad de Filosofía y Humanidades, Universidad Nacional de Córdoba) y licenciada en Historia (Facultad de Filosofía y Humanidades, Universidad Nacional de Córdoba).marianafabra@gmail.com 


\section{Resumen}

Se presenta una reflexión en torno a la cartografía social como propuesta teórica-metodológica participativa de investigación para el estudio, el análisis y la socialización del patrimonio arqueológico, partiendo de una experiencia de trabajo de campo en la localidad de Miramar (Córdoba, Argentina). Para esto, aplicamos diferentes técnicas de mapeo colectivo, estableciendo un diálogo entre trabajadores del museo, vecinos, turistas e investigadores sobre patrimonio, desde una perspectiva colaborativa y transdisciplinaria, para analizar las oportunidades y desafíos que nos ofrece la cartografía social para los estudios patrimoniales. Se concluye que a partir de las prácticas cartográficas críticas y participativas realizadas se fueron abriendo camino nuevas formas de entender el espacio habitado que dan prioridad al sentir de la comunidad en la construcción del paisaje cultural local. En este sentido, se busca aportar nuevas estrategias metodológicas para la investigación patrimonial.

Palabras clave: cartografía social, investigación del patrimonio, metodología participativa, patrimonio arqueológico.

\section{Abstract}

This paper reflects on social cartography as a participatory theoretical-methodological research proposal for the study, analysis and sharing of archaeological heritage, based on a fieldwork experience in the town of Miramar (Córdoba, Argentina). For this purpose, we apply multiple collective mapping techniques, engaging museum workers, neighbors, tourists, and researchers in a dialogue on heritage - from a collaborative and transdisciplinary perspective - to discuss the opportunities and challenges offered by social mapping to heritage studies. It is concluded that critical and participatory cartographic practices gave rise to new ways of understanding the inhabited space that prioritize community's feelings on the construction of the local cultural landscape. Thus, this article seeks to contribute new methodological strategies for heritage research.

Keywords: Social cartography, heritage research, participatory method, archaeological heritage. 


\section{Resumo}

Apresenta-se uma reflexão à volta à cartografia social como uma proposta teórico-metodológica participativa de pesquisa para o estudo, a análise e a socialização do patrimônio arqueológico, com base em uma experiência de trabalho de campo na cidade de Miramar (Córdoba, Argentina). Para isso, aplicamos diferentes técnicas de mapeamento coletivo, estabelecendo um diálogo entre trabalhadores do museu, vizinhos, turistas e pesquisadores sobre patrimônio, de uma perspectiva colaborativa e transdisciplinar, para analisar as oportunidades e os desafios que nos oferece pelo mapeamento social para os estudos de patrimônio. Conclui-se que, a partir das práticas cartográficas críticas e participativas realizadas, começaram a se abrir novas formas de entender o espaço habitado que dão prioridade ao sentir da comunidade na construção da paisagem cultural local. Nesse sentido, busca-se fornecer novas estratégias metodológicas para a pesquisa do patrimônio.

Palavras chaves: mapeamento social, pesquisa de patrimônio, metodologia participativa, patrimônio arqueológico.

\section{Introducción}

Este artículo aborda y desarrolla el enfoque de la cartografía social a partir de una experiencia de campo que contempló la puesta en práctica de un ciclo de talleres denominado "El patrimonio arqueológico de Miramar a través de la cartografía social (Córdoba Argentina)"5. El trabajo constó de cinco talleres en los que se emplearon una variedad de técnicas de mapeo colectivo junto con otras técnicas etnográficas, como las entrevistas grupales e individuales, la observación participante y los grupos de reflexión, y se llevaron a cabo durante los meses de abril y mayo de 2017. Esta investigación se llevó a cabo en el marco de la tesis doctoral de una de las autoras (Valeria Belén Martin

5 El ciclo fue avalado y certificado por la Secretaría de Extensión Universitaria de la FFyH, UNC.

Vol. 24 N. ${ }^{\circ} 2$

julio - diciembre de 2019

pp. $125-148$
Silva $)^{6}$, de modo que este trabajo forma parte de una investigación más amplia, que busca indagar en los mecanismos de conceptualización y los usos del patrimonio arqueológico que subyacen en los procesos de patrimonialización de sitios arqueológicos en la región Centro de Argentina, de la cual la provincia de Córdoba forma parte.

La localidad de Miramar se presenta como un enclave único en la región en el cual confluye una gran diversidad de patrimonios, ya que la cercanía inmediata del poblado con la laguna de Mar Chiquita y su variación hidrológica a lo largo del tiempo han influido en la configuración del terri-

6 Este artículo se desprende de una tesis doctoral en curso del Programa de Doctorado en Patrimonio de la Universidad de Huelva, denominada "Teoría y Praxis sobre procesos de patrimonialización en sitios arqueológicos: experiencias y propuestas para la Región Centro de Argentina". llevada a cabo por la magíster Valeria Belén Martin Silva. 
torio y la preservación de los restos arqueológicos en la región. Además, se encuentra en desarrollo el proyecto de creación de un futuro parque nacional que plantea retos en cuanto a cuestiones de gobernanza, actividades productivas campesinas, actividades turísticas y usos de la tierra, razones por las cuales Miramar se nos presentó como el lugar idóneo para indagar sobre las dialécticas existentes entre comunidad, territorio, turismo, patrimonio y arqueología.

En este sentido, se parte de proponer que la gestión patrimonial en torno a la patrimonialización de sitios arqueológicos en muchos casos carece de una gestión integrada, ya que los planes desarrollados terminan centrándose en aspectos formales y técnicos de la puesta en valor del recurso patrimonial, pero no se propician espacios de participación, sociabilización o apropiación social del mismo.

El objetivo de este trabajo es reflexionar sobre las oportunidades y los desafíos de la construcción de mapas participativos como herramientas de análisis para los estudios patrimoniales. Abordamos el análisis espacial del patrimonio miramarense a partir de la elaboración de mapas que visibilizaron algunos aspectos difícilmente perceptibles desde la cartografía convencional ${ }^{7}$, pero presentes en la memoria de los miramarenses como, por ejemplo, el patrimonio arqueológico e histórico que fue desapareciendo a través del tiempo a causa de las fluctuaciones hidrológicas de la laguna de Mar Chiquita. Asimismo, se buscó generar sinergias para una mayor inclusión social.

En este contexto, la cartografía social (CS en adelante) se presenta como la herramienta idónea para

7 Denominamos cartografía convencional a los mapas, cartas y planos surgidos a partir de los métodos de representación euclidianos tradicionales. entrever los procesos, las construcciones y las significaciones del espacio habitado, lo cual permite el reconocimiento, la articulación y el manejo del saber colectivo en los procesos de identificación con el territorio, el patrimonio y los propios actores que lo habitan (Carballeda, 2012).

\section{Aspectos teóricos-}

metodológicos: el mapa, el

\section{territorio y la cartografía social}

Los mapas y las prácticas cartográficas han sido un instrumento de poder. Han sido realizados generalmente por cartógrafos, religiosos, funcionarios o expertos académicos, es decir que la producción de mapas oficiales ha sido una práctica orquestada, en muchos casos, desde intereses externos a las realidades locales de las áreas mapeadas. Como plantea Anderson (1991), la cartografía fue concebida como una herramienta clasificatoria para apropiar territorios, recursos y poblaciones para el mismo Estado moderno. Para el caso de América, también en el período colonial por las Coronas europeas. En este sentido, las políticas de ordenamiento y planeamiento territorial han tenido, en términos generales, una nula o marginal participación de la comunidad local en los procesos de gestión territorial (Montoya Arango, García Sánchez \& Ospina Mesa, 2014).

En contraposición a estos lineamientos, a comienzos de la década de 1980 surge una nueva corriente denominada cartografia posmoderna por varios autores (Crampton, 2001; Dodge, Kitchin \& Perkins, 2009), que concibe la cartografía y los mapas con diferentes enfoques y perspectivas e identifica los mapas como un mensaje social (Montoya Aran- 
go, 2007) que aboga por dar voz al conocimiento subalterno, transcender las rígidas fronteras de las disciplinas y proponer una "producción del conocimiento con y desde los territorios" (Mignolo, 2011). Dentro de este marco, encontramos la CS como una propuesta conceptual y metodológica participativa y colaborativa de investigación en un territorio determinado que viene a proponer un involucramiento activo de las personas en todo el proceso de pesquisa (Habegger \& Mancilla, 2005). Desde una perspectiva posmoderna, la CS aporta tanto a la teoría como a la praxis cartográfica. Los mapeos colectivos forman parte de las llamadas “nuevas prácticas cartográficas", en donde el mapeo es concebido desde una práctica colectiva y horizontal y la creación de mapas surge de un proceso de intercambio, debate y consenso (Azócar, 2017)

Como modo colectivo de crear conocimiento, la CS se aleja de los mapas tradicionales obrados de modo vertical, es decir que el mapa social es consensuado, el "cartógrafo" es el colectivo, no hay cartografía sin comunidad (Diez Tetamanti, 2012). En este proceso de construcción la comunidad se reconoce en el espacio, en su espacio vital (Acosta Bono, 2011).

Además, la CS se fundamentada en los principios metodológicos de la investigación-acción participativa (IAP), en la medida en que la comunidad es agente central del proceso de generación de conocimiento (García, 2005). Los actores sociales y sus saberes son clave para el entendimiento de las realidades territoriales como espacios de contención de los escenarios sociales (García, 2005; Carballeda, 2012; Castro Jaramillo, 2016). Y es desde esa construcción colectiva del conocimiento que damos cuenta y razón de la subjetividad del espacio vital, lo cual nos permite entender la sociedad civil en su espacio, en su territorio, y considerar a las personas como sujetos pensantes, críticos y propositivos y no como meros objetos receptores de conocimientos (Andrade \& Santamaría, 2010). En la Figura 1 se presenta un diagrama sobre cómo conceptualizamos la CS.

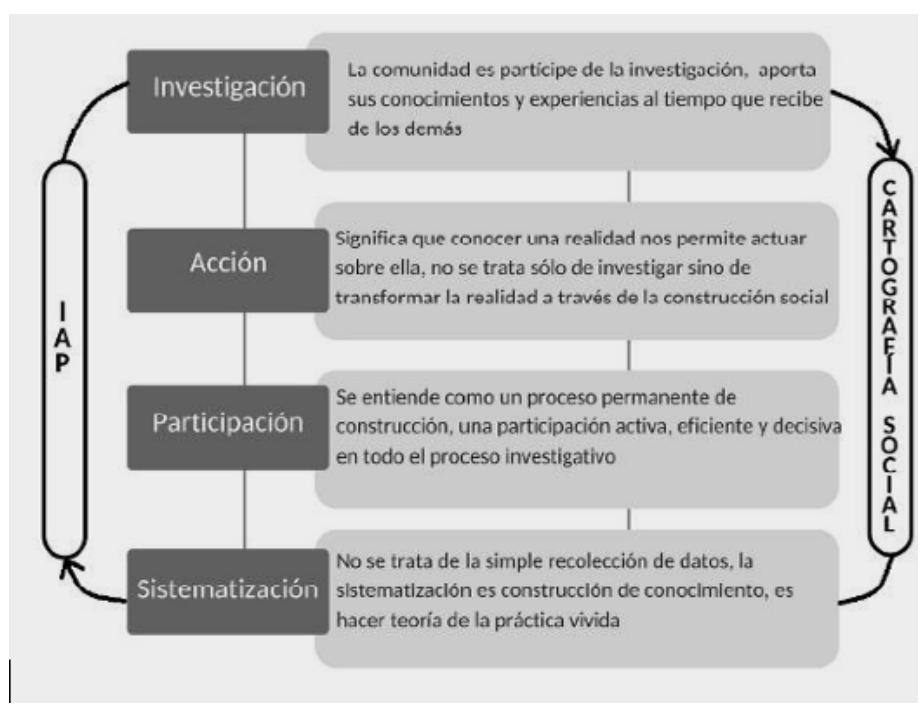

FIGURA 1.

Fundamentos conceptuales de la

investigación-acción participativa (IAP) en los que se basa la metodología de la cartografía social.

Fuente: Elaboración propia a partir de Castro Jaramillo (2016). 
Por medio de estas otras cartografías generadas en el seno de la CS se construye conocimiento desde el compromiso social y la participación para la transformación de una comunidad, y para la puesta en valor de lo que ellos consideran patrimonio, más allá de las declaratorias estatales. El territorio se amplía y alarga cuando el participante se reconoce como un elemento que puede transformar el espacio; con el mapeo colectivo se conoce más el territorio y se amplían las posibilidades de comando y las acciones comunitarias. Con esto se traslada el eje de poder, que hasta ese momento se centraba en los que concentraban el conocimiento universitario y disciplinar (Diez Tetamanti \& Rocha, 2016).

Una de las herramientas esenciales de la CS es el mapeo colectivo, también conocido como mapeo participativo, mapeo social o mapeo comunitario (Ganter, Sandoval, García \& De la Fuente, 2015), que algunos autores definen como:

Un proceso de creación que subvierte el lugar de enunciación para desafiar los relatos dominantes sobre los territorios, a partir de los saberes y experiencias cotidianas de los participantes. Sobre un soporte gráfico y visual se localizan las problemáticas más acuciantes del territorio identificando a los responsables, reflexionando sobre conexiones con otras temáticas y señalizando las consecuencias (Ares \& Risler, 2013, p. 12).

En el ámbito latinoamericano, del cual formamos parte, la práctica de la CS encuentra sus orígenes en la generación de mapas de las tierras y los territorios habitados por pueblos indígenas. Este proceso se remonta, dependiendo de la región, a las décadas de 1970 (suroccidente colombiano) y
1980 (América Central). Otra de las líneas de estudio que han tenido un largo recorrido han sido las cartografías en torno a las problemáticas de los derechos territoriales de comunidades indígenas, colectivos y grupos locales (Andrade, 2001; Barroso Hoffman, 2010; Sletto, 2010; Vélez Torres, Rátiva Gaona \& Varela Corredor, 2012; Almeida, 2013; Montoya Arango et al., 2014; Sletto, Bryan, Torrado, Haley \& Barry, 2013).

Igualmente, en los últimos años han ido creciendo las investigaciones que hacen uso de la CS para estudios de índole patrimonial, promoviendo así la participación de los pobladores en el proceso de construcción de saberes y producción de conocimiento sobre el paisaje cultural (Aichino, De Carli, Zabala \& Fabra, 2012; Vélez Torres et al., 2012; Ares \& Risler, 2013; Blasco, Lamas, Gentile, Villamarzo \& Gianotti, 2014; Martins \& Baeta Leal, 2015).

Todos estos procesos de mapeo han sido muy diversos de acuerdo con las particularidades de cada región y han abierto nuevas perspectivas para concebir el territorio habitado y visibilizar los procesos de cambio territorial desde la mirada comunal (Salamanca, 2012). Estos productos cartográficos surgidos desde la CS crean mapas que no solo representan al territorio, sino que lo producen y lo transforman (Montoya Arango, 2007), creando así nuevas prácticas para "la apropiación y conocimiento de todas las dimensiones del territorio: la físico-biótica y abiótica, físico-espacial y sociocultural" por parte de la comunidad local (Patiño Jiménez, 2014, p. 11).

A partir de las conceptualizaciones de la CS se concibieron los talleres de mapeo colectivo desarrollados en la localidad de Miramar de Ansenuza. Siempre se parte de un entendimiento del patrimo- 
nio como una construcción social, es decir que no es un elemento que exista en la naturaleza ni es algo dado o un fenómeno social universal (Prats, 1997, p. 20), sino que es "una construcción sociocultural que adquiere valor para aquel grupo que lo realizó, heredó y conserva. Por ser una construcción que se desarrolla en el tiempo y para unos determinados fines, el patrimonio es dinámico, cambiante" (Viladevall, 2003, p. 18). En relación con el patrimonio arqueológico, lo entendemos como la parte de nuestro patrimonio material para la cual los métodos de la arqueología nos proporcionan la información básica. Engloba todas las huellas de la existencia del hombre y se refiere a los lugares donde se ha practicado cualquier tipo de actividad humana, a las estructuras y los vestigios abandonados de cualquier índole (Consejo Internacional de Monumentos y Sitios Culturales [Icomos], 1990).

En cuanto al patrimonio en el contexto territorial, entendemos que el patrimonio y el paisaje son parte de "una trama de significaciones que el propio hombre ha tejido en su propia vida social" (Geertz, 2003). Los paisajes se conciben como productos de un entramado de relaciones ecológicas, culturales y sociales que se materializan en un territorio específico, y los patrimonios se conciben como nodos que emergen en las tramas de relaciones del territorio (Ladrón de Guevara González, Toro Balbontín, Prieto Véliz \& Chávez Valdivia, 2015). Esto quiere decir que solo podremos abordar una aproximación a los paisajes culturales presentes y pasados si partimos de una gestión integral del patrimonio. Una visión holística a todos los niveles, en un todo global o integral en el que el patrimonio arqueológico es entendido desde su paisaje circundante, sus patrones de asentamiento y aprovechamiento de recursos y su estructura simbólica para llegar a caracterizar el paisaje cultural, ensan- chando así la noción de registro arqueológico a una mayor escala conceptual y espacial, lo cual plantea nuevos desafíos para la arqueología y la integración de su accionar dentro de la planificación y la gestión del territorio (Ballesteros Arias, Otero Vilariño \& Varela Pousa, 2005).

\section{El contexto de investigación, el caso de Miramar}

Por ordenanza municipal, en el año 2014 la localidad de Miramar cambió su nombre oficial a Miramar de Ansenuza, respondiendo así a una propuesta realizada por el gobernador de Córdoba de ese entonces, con el fin de ayudar a posicionar mejor el destino turístico de Miramar diferenciándolo de otras poblaciones con el mismo nombre. Cabe destacar que este proceso administrativo se realizó sin contemplar un referéndum o consulta popular, es decir que no se generó un espacio para que la comunidad pudiera expresar su postura al respecto, por lo que hoy en día este nombre sigue generando tensiones, ya que en la región no se reconoce que Ansenuza sea un vocablo indígena para nombrar a la gran laguna Mar Chiquita sino que, al contrario, la palabra es de origen europeo y según diferentes investigaciones históricas sería el nombre con el que los españoles denominaron al terreno circundante a la laguna ${ }^{8}$. Por tal motivo a la largo del texto usamos el nombre de Miramar, ya que así lo nombran los participantes de los talleres.

La localidad se encuentra ubicada en el noreste de la provincia de Córdoba (Argentina), en el departamento San Justo, sobre la costa sur de la

8 Ver: Miramar ahora se llama Miramar de Ansenuza (2014); Miramar: Concejo aprobó el cambio de nombre a la localidad (2014). 
gran laguna de Mar Chiquita (ver Figura 2). Es la única población ubicada en la ribera de esta laguna, emplazada en una zona urbanizada que cuenta con aproximadamente 2.023 habitantes (Instituto Nacional de Estadística y Censos de la República Argentina [Indec], 2010). Las actividades principales del municipio se concentran en la actividad

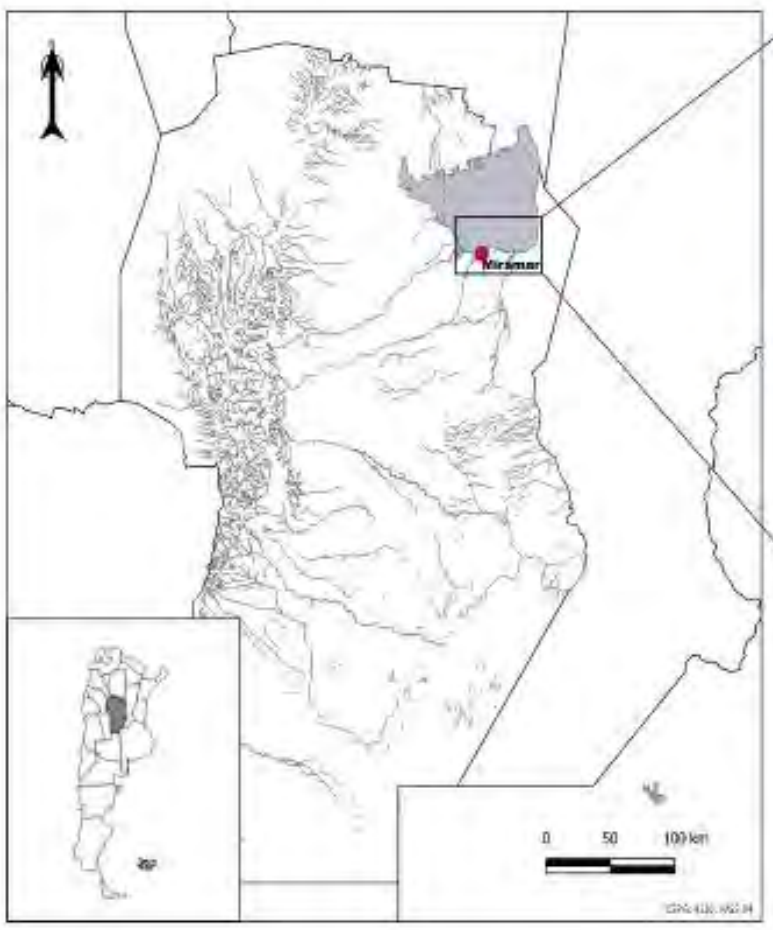

La laguna de Mar Chiquita es la mayor cuenca cerrada de Latinoamérica, con una extensión de más de $6.000 \mathrm{~km}^{2}$, declarada por la provincia de Córdoba en el año 1976 como Refugio de Vida Silvestre Depresión Salina de los Bañados del Río Dulce y Laguna Mar Chiquita (Decreto n ${ }^{\circ}$ 4906/76). Luego, en el año 1994, como Reserva Natural de Uso Múltiple Bañados del Río Dulce y Laguna de Mar Chiquita (Decreto ${ }^{\circ}$ 3115/94), y en el año 2002 como Sitio Ramsar "Bañados del Río Dulce y Laguna Mar Chiquita" (Bucher, Coria, Curto \& Lima, 2006). Actualmente la laguna Mar Chiquita turística (turismo de salud, que aprovecha las propiedades curativas del agua y el barro de la laguna, turismo ecológico y turismo de ocio) y criaderos de nutria que han dado origen a una floreciente industria peletera con prendas de piel y cuero de gran calidad (Zapata, 2011).

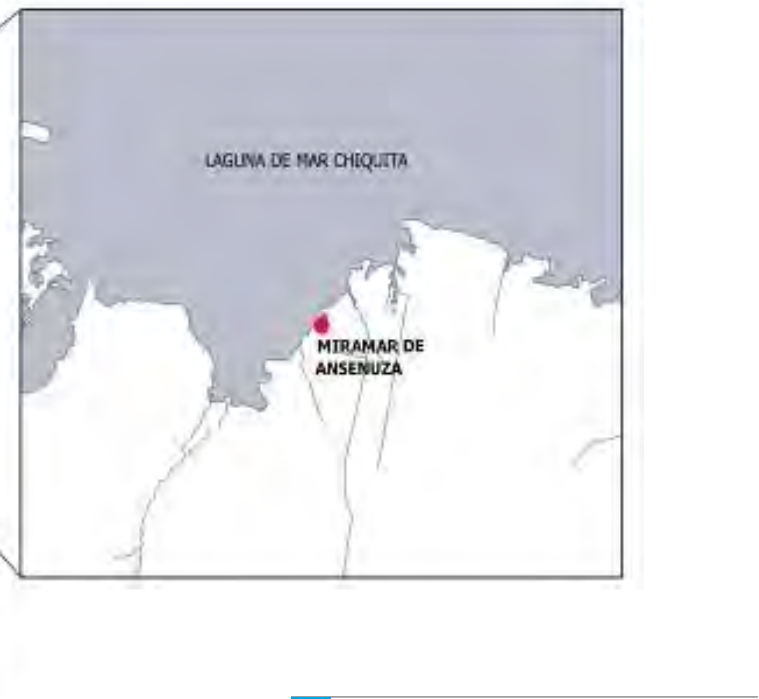

FIGURA 2.

Localización del área de estudio. Fuente: Elaboración propia

y los Bañados del Río Dulce se encuentran en proceso de ser transformados en el Parque Nacional Ansenuza, lo que la convertiría en el área natural protegida más grande del país. Asimismo, la particularidad del paisaje, la variedad de aves (más de 300 especies) y las saludables propiedades de la zona se presentan como un enclave único en la región, en el que confluye una gran diversidad de patrimonio natural y cultural que han definido el perfil turístico de la localidad (Leiva, 2014).

La laguna ha moldeado no solo el paisaje y la fisonomía de la región, sino las estrategias de sub- 
sistencias de las poblaciones humanas. Las variaciones hidrológicas han sido frecuentes durante al menos los últimos 20.000 años, alternando fases frías y secas con húmedas y cálidas (Piovano, Ariztegui, Córdoba, Cioccale \& Sylvestre, 2009). A lo largo de estas fases húmedas la ciudad ha sufrido tres grandes inundaciones que han afectado al entramado urbano (en 1958, 1977 y 2003). La más grave de ellas se remonta al año 1977, cuando quedaron sepultadas bajo las aguas de la laguna 37 manzanas del radio urbano y se perdieron más de sesenta establecimientos comerciales, edificios públicos y 168 casas de familia (Zapata, 2011).

\section{Mapeando la realidad}

\section{patrimonial de Miramar}

Desde el año 2005, y a partir de la formalización del Programa de Arqueología Pública (PAP) ${ }^{9}$ como programa de extensión universitaria en el año 2011, se fueron desarrollando en diferentes localidades de la provincia de Córdoba actividades de sociabilización del patrimonio en la línea metodológica de la educación patrimonial, en el contexto de intervenciones del PAP frente al hallazgo de restos arqueológicos en riesgo ${ }^{10}$ (Fabra, Roura Galtés \& Zabala, 2008; Zabala \& Fabra, 2012; Fabra \& Zabala, 2015; Zabala, Fabra, Aichino \& De Carli, 2015).

9 El programa depende del Instituto de Antropología de Córdoba-Conicet, el Museo de Antropología y la Secretaría de Extensión Universitaria de la Facultad de Filosofía y Humanidades, Universidad Nacional de Córdoba. Es dirigido por dos de las autoras del trabajo (Mariela Eleonora Zabala y Mariana Fabra)

10 El PAP lleva adelante actividades orientadas a establecer lazos entre los saberes académicos y otros saberes generados en torno al patrimonio en ámbitos extrauniversitarios, permitiendo así la participación de la comunidad en las tareas de rescate, protección, revalorización y apropiación de los bienes arqueológicos en situación de riesgo.
En los últimos años, este equipo de investigación y extensión ha ido incursionado en talleres de CS que se han realizado en San Carlos Minas en el año 2011 (departamento de Minas, Córdoba) y en Miramar en 2012 (departamento de San Justo, Córdoba) (Aichino, De Carli, Zabala \& Fabra, 2013; Zabala, Fabra, Aichino \& de Carli, 2016), localidades en donde se habían realizado tareas de rescates arqueológicos. Desde un planteamiento participativo, se fomentó el intercambio de saberes, promoviendo así espacios de diálogo en relación con los patrimonios locales, el modo en que se conciben y sus políticas de conservación (Aichino et al., 2012).

En este contexto y para dar continuidad y profundidad a las tareas que se venían realizando, se propuso un ciclo de talleres de CS en Miramar. Para ello, se promovió la creación de espacios de encuentro, mediación y sociabilización con la población local como un medio para adentrarnos en los modos en que se percibe y se construye la experiencia con el espacio, es decir la experiencia geográfica. A su vez, los talleres fueron concebidos como entornos de experimentación que permitieran emplear diferentes técnicas de mapeo colectivo en un mismo lugar para pensarlo como un proceso pragmático, con una visión hacia el futuro, que posibilitara reflexionar sobre los esquemas de gestión y proyectar propuestas desde y no exclusivamente para los ciudadanos (Martin Silva, 2016).

Al arribar a esta localidad, establecimos un nexo muy cercano con el Museo de Ciencias Naturales de la Región de Ansenuza "Aníbal Montes" - en adelante, MCNAM - debido a sus años de trabajo con el Museo de Antropología y el PAP, que tendieron puentes para que este fuera el lugar para desarrollar el trabajo de campo durante la estancia. 
Fue el espacio desde el que empezamos a relacionarnos con la comunidad local, y además cedieron su sala de usos múltiples para el desarrollo de varios de los talleres realizados.

El ciclo de talleres "El patrimonio arqueológico de Miramar a través de la cartografía social (Córdoba, Argentina)", constó de cinco sesiones de mapeo colectivo a lo largo de dos meses (marzo y abril de 2017) en las que participaron 73 personas. Los participantes de los talleres fueron en su mayoría población adulta, con un $70 \%$ de individuos femeninos, a excepción del segundo taller de Mapeo al Paso, en donde participaron niños y jóvenes, aunque estuvieron abiertos a todo público.

El trabajo desarrollado en el ciclo, sumado a otras técnicas etnográficas como entrevistas, grupos de discusión y observación participante, permitieron entablar una relación de cercanía con la comunidad local y se llegó a establecer lazos de confianza con algunos de los participantes más allá del ámbito de los talleres, por ejemplo, en eventos locales, actos patrios, comidas informales e incluso actividades deportivas y recreativas.

Durante el ciclo asumimos un rol de facilitadores en el proceso de construcción de nuevos saberes y los participantes pasaron a ser los protagonistas de este proceso, lo cual propició espacios de empoderamiento comunal. Se abordó la realidad local desde una perspectiva integral e integradora, sin imponer nuestra visión del paisaje y alejándonos de la figura del investigador como poseedores del saber, en el entendimiento de que estos procesos cartográficos deben ser concebidos y vividos como procesos permanentes de formación y aprendizaje. Esto fue factible porque no somos oriundas ni habitamos en la localidad, entonces el lugar, de algún modo, nos es extraño.
En una primera instancia llevamos a cabo el ta1ler Diagnóstico Patrimonial Participativo en el MCNAM, que contó con la participación de 10 asistentes ( 8 mujeres y 2 hombres). Se trabajó sobre el concepto de patrimonio y patrimonio arqueológico a partir de una serie de preguntas disparadoras. En un segundo momento realizamos una versión adaptada de un sociograma, una técnica que buscó visibilizar las relaciones entre los diferentes agentes claves (grupos de alto poder, población organizada y población no organizada) (Jiménez, Vela, Ramírez \& García, 2013). La adaptación de esta técnica fue denominada cultugrama porque se agregó la variable patrimonio, es decir que la finalidad de la actividad fue dilucidar el entramado de las relaciones de los diversos grupos sociales con el patrimonio local. Este ejercicio de exploración también permitió ajustar y reorientar los siguientes talleres a partir de los desafíos particulares surgidos de este mapeo inicial, donde se detectaron los actores claves en la gestión del patrimonio local, tanto del ámbito administrativo como del tejido organizativo local. De esta forma, la Cooperativa Eléctrica y de Servicios Públicos Miramar Ltda. (que tiene a su cargo el Museo Fotográfico Dante Marchetti y el Museo Capilla San Antonio, primera capilla croata de la provincia de Córdoba) y el Museo de Ciencias Naturales Aníbal Montes surgen como las instituciones relacionadas con la protección, la gestión y la conservación del patrimonio (ver Figuras $3 a$ y $3 b)$. Para nuestra sorpresa, ninguna es una institución estatal.

El segundo taller realizado fue el de Mapeando al Paso: construimos el mapa de Miramar, para lo cual se empleó la técnica del mapeo en distintos espacios de la ciudad previamente elegidos. El taller se extendió por cuatro días y contó con 
la participación de 46 personas (21 miramarenses y 25 turistas) de diferentes grupos etarios, desde los 10 años a los 77 años. Se desarrolló en sitios neurálgicos de la ciudad como la plaza principal (Plaza de las Américas, esquina calle Libertad y Buenos Aires) y el paseo de la costanera (a la vera de laguna de Mar Chiquita), que fueron los puntos elegidos debido al alto tránsito de peatones y la visibilidad que poseen, además de su cercanía con otros puntos importantes de la ciudad: en el caso de la plaza principal, se encuentra frente a la terminal de colectivos y a unos cien metros del MCNAM.

Se usaron pictogramas en un mapa de la ciudad de Miramar (tamaño A2) ya impreso en folletería oficial de la Oficina de Turismo, con el fin de (re)imaginar el territorio normalizado y crear un nuevo mapa alterno, alejado de la visión estandarizada de la ciudad. Si bien cada pictograma tenía un epígrafe sugerido para la actividad, se contemplaba que se pudieran combinar dos o más pictogramas para crear una nueva significación, permitiendo así un ambiente de trabajo colaborativo, abierto y reflexivo. Para la confección de los pictogramas se tomó como referencia el $\mathrm{Ma}$ nual de mapeo colectivo de Ares y Risler (2013), y diseñamos una serie de pictogramas, antes del trabajo de campo, que pudieran dar cuenta de las relaciones de asociatividad o conflicto en torno a la arqueología, la comunidad y el patrimonio. Por ejemplo, pictogramas que representaban basurales, contaminación, destrucción del patrimonio, patrimonio abandonado, bioreservas naturales y ecoturismo (ver Figura 3c). Esto fue posible por nuestro conocimiento previo de la ciudad.

Esta fue la única actividad que incluyó la participación de turistas, pero esta particularidad fue buscada, ya que se pretendía comparar las percepciones de los turistas en relación con el patrimonio arqueológico de Miramar con la opinión de quienes habitan y transitan el territorio local cotidianamente. Miramar es un destino turístico de la provincia de Córdoba desde comienzos del siglo XX, que se hizo "famoso" por sus aguas curativas para dolencias óseas. Esta provincia no tiene salida al mar, por eso esta laguna también es una oferta de veraneo (ver Figura 3d).

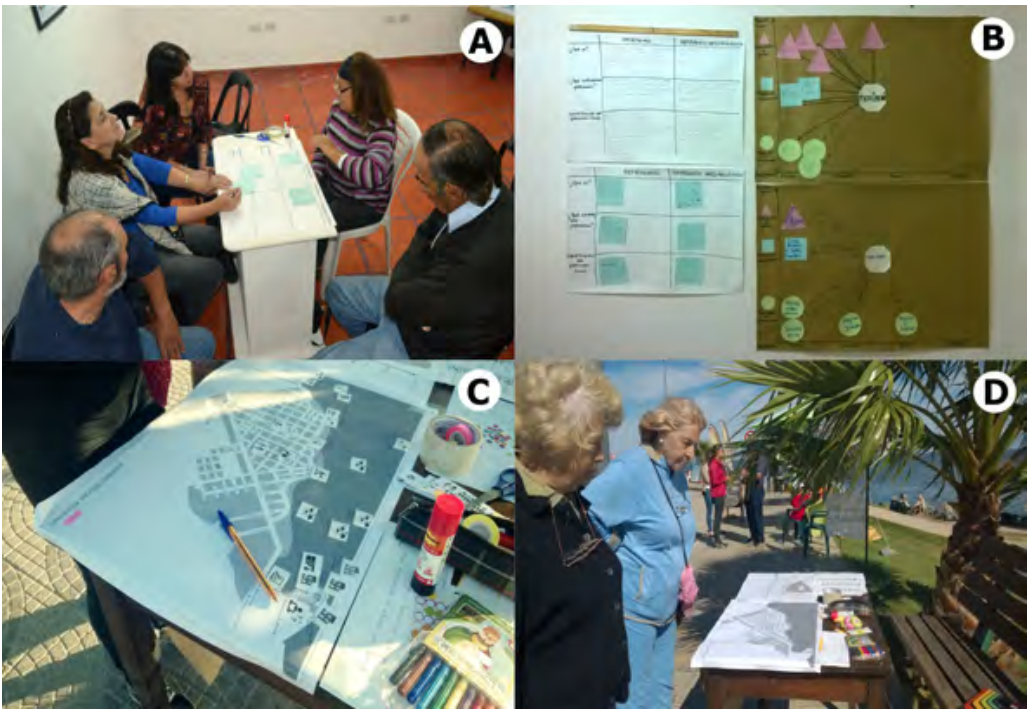

Vol. 24 N. ${ }^{\circ} 2$

julio - diciembre de 2019 pp. $125-148$
FIGURA 3.

Talleres Diagnóstico Patrimonial Participativo y Mapeando al Paso: a. Participantes del taller Diagnóstico Patrimonial Participativo; b. Mapas conceptuales sobre patrimonio y patrimonio arqueológico y cultugramas resultantes del taller Diagnóstico Patrimonial Participativo; c. Mesa de mapeo del taller Mapeando al Paso: construimos el mapa de Miramar; d. Participantes del taller Mapeando al Paso Fuente: Elaboración propia. 
Algunos temas que siguieron a la actividad fue la señalización del uso de cuatriciclos a la vera de la laguna, lo que implicó hace unos años la destrucción de restos arqueológicos y del patrimonio natural). Además, se plasmaron los recuerdos de lo que se perdió en la última gran inundación de la ciudad, ese patrimonio perdido y abandonado; en cambio, el mapa creado por los turistas se centró en las actividades turísticas más típicas (avistamiento de flamencos y visitas al Hotel Gran Viena, entre otras), sin dar cuenta del gran valor de la biodiversidad que alberga la laguna (como las 329 especies de aves) o del valor arqueológico que existe en la zona de Miramar o Mar Chiquita.

El siguiente taller desarrollado se tituló "La cartografía comunitaria como herramienta para la co-construcción del patrimonio local" y fue llevado a cabo en el MCNAM. El taller contó con la

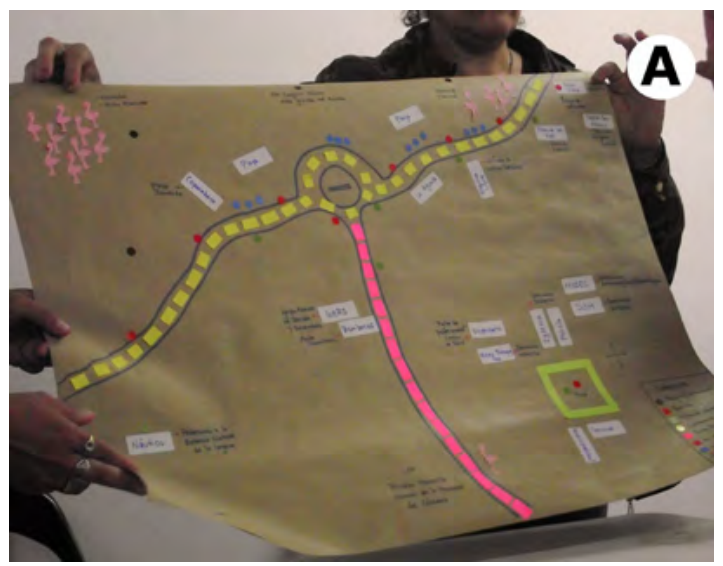

participación de 10 asistentes, todas mujeres adultas, y se trabajó en mapas temporales para realizar un ejercicio de reflexión temporal colectiva. Nos centramos en dos escenarios temporales: presente (permite mirar la situación actual, cómo viven su presente, pero a la vez posibilita reflexionar sobre el pasado y las transformaciones del territorio y la comunidad) y futuro (qué queremos para Miramar, qué representa los deseos de la comunidad para el día de mañana). La creación y la construcción de los mapas patrimoniales fue realizada en afiches blancos con el fin de que los participantes materializaran su territorio de modo creativo y como lo perciben. Se debatió al interior de cada grupo sobre los elementos que se querían señalizar, lo cual dio lugar a un espectro de opiniones, voces y saberes que quedaron plasmados en los mapas (ver Figuras $4 \mathrm{a}$ y $4 \mathrm{~b})$.

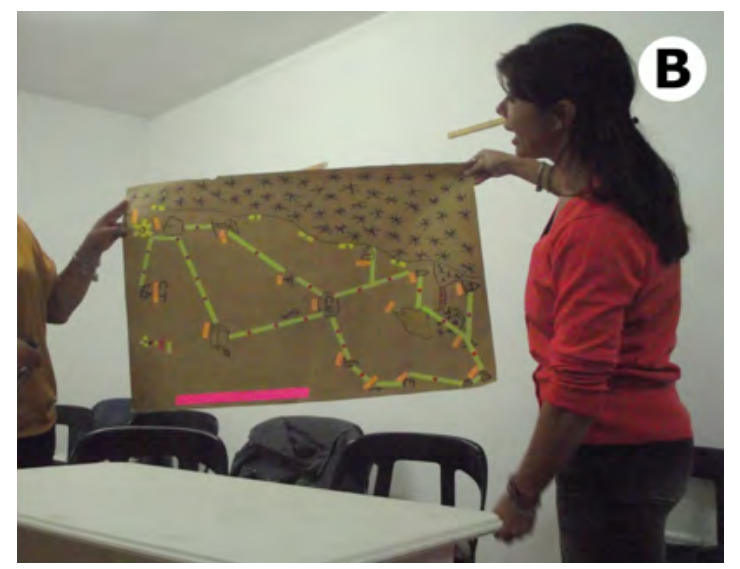

FIGURA 4.

Taller “La cartografía comunitaria como herramienta para la co-construcción del patrimonio local": a. Mapa presente de Miramar; b. Mapa futuro de Miramar Fuente: Elaboración propia.

En el mapa del presente los hitos principales se marcaron al rededor de la laguna, lo que vuelve a reforzar la idea de que la laguna ha moldeado los modos en que se desenvuelve la comunidad, y en el mapa del futuro quedó expresado ese deseo de un turismo respetuoso con el medio natural, que vuelva a las raíces de la actividad turística en Miramar en torno a un turismo de salud y naturaleza. 
Otro aspecto muy importante en este mapa fue el de rescatar las zonas inundadas de la ciudad a través de cartelería, que muestre cómo eran an- tes esos lugares que ahora se encuentran bajo las aguas de la laguna.

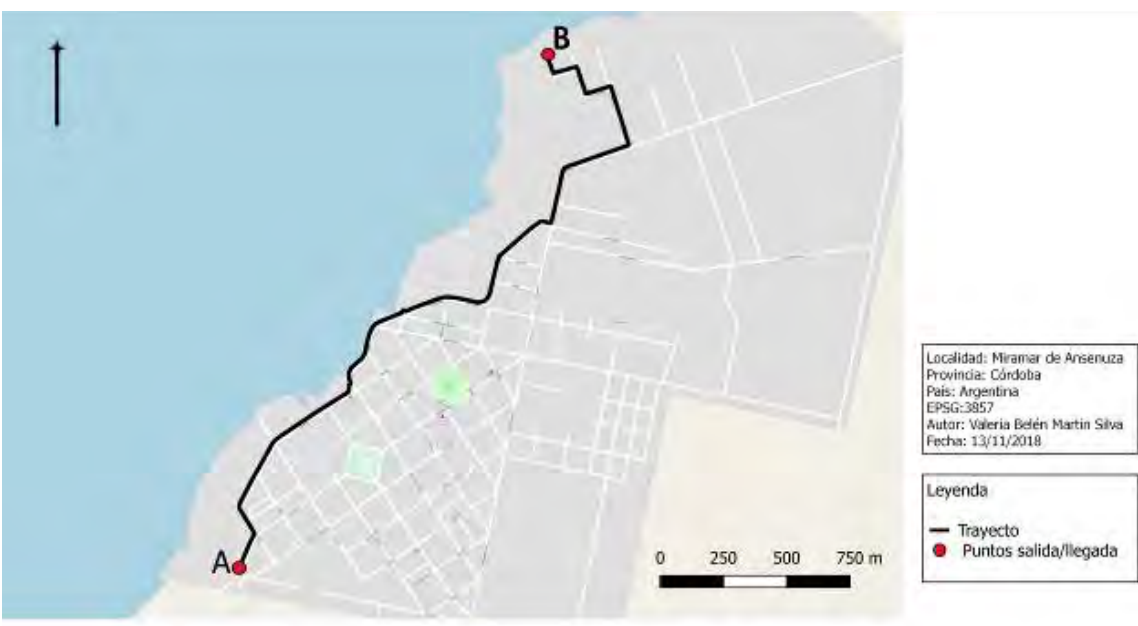

FIGURA 5.

Recorrido de la Deriva desde el punto A (sitio arqueológico Ex Camping Municipal) al punto B (sitio histórico Hotel Gran Viena)

Fuente: Elaboración propia a partir de imagen satelital de Google Earth.
El tercer taller se denominó "La Deriva aplicada al estudio de la gestión patrimonial: cartografías mentales en Miramar (Córdoba)" y participaron cuatro mujeres ${ }^{11}$. Llevamos a cabo una deriva, técnica usada en el diagnóstico rural participativo que plantea una práctica de conocimiento e interacción a partir de un recorrido por el espacio habitado, sea este una ciudad o un espacio rural, siguiendo lógicas no habituales, ya sean estas azarosas o construidas (Paez i Blanch, 2014). Para pensar el recorrido mantuvimos conversaciones con Hugo Giraudo, guía del MCNAM y gran conocedor de la zona, que permitieron configurar el recorrido inicial de la Deriva, que consistió en caminar por sitios históricos y zonas arqueológicas del lugar ${ }^{12}$ con gente de la localidad

11 Consideramos que el bajo número de participantes se debió en parte al planteamiento del cronograma de la actividad, que suponía una extensión horaria un poco larga para las actividades a las que están generalmente acostumbrados a asistir.

12 El recorrido contempló nueve paradas a lo largo del paseo de la Costanera de la ciudad a la vera de la laguna de Mar (ver Figura 5), a la vez que se intercambiaban con ellos preguntas e impresiones con el fin de sistematizar los primeros sentimientos que tienen sobre el territorio que habitan.

Este recorrido fue guiado en parte por las participantes mientras creaban espacios de debate sobre temas observados en el terreno y compartían historias y recuerdos de los lugares visitados (ver Figura 6a). Lo vivido y lo registrado fotográficamente durante la Deriva fue plasmado en un mapa que permitió la construcción de los paisajes arquetípicos del lugar visitado a partir de los relatos visuales de los participantes. La puesta en común de la Deriva y la construcción del mapa a partir de los relatos visuales fueron desarrolladas en el MCNAM (ver Figura 6b). Cabe aclarar que debido

Chiquita (sitio arqueológico Ex Camping Municipal, sitio histórico Hotel Miramar, sitio arqueológico Schlemmer, sitio histórico Hotel Copacabana, sitio histórico antigua urbanización, sitio arqueológico Abrate, sitio arqueológico Viena 2, sitio arqueológico Viena y sitio histórico Hotel Gran Viena). 
a la extensión de la actividad y por problemas de disponibilidad de algunos de los participantes la segunda parte del taller no pudo ser realizada ese mismo día y se concretó tres días más tarde, cuando podían asistir todos.

Con la Deriva se consiguió redescubrir el territorio y acercar ese patrimonio arqueológico oculto y, en algunos casos, perdido por la subida de los niveles de la laguna que ha ocasionado que varios sitios arqueológicos actualmente se encuentren bajo las
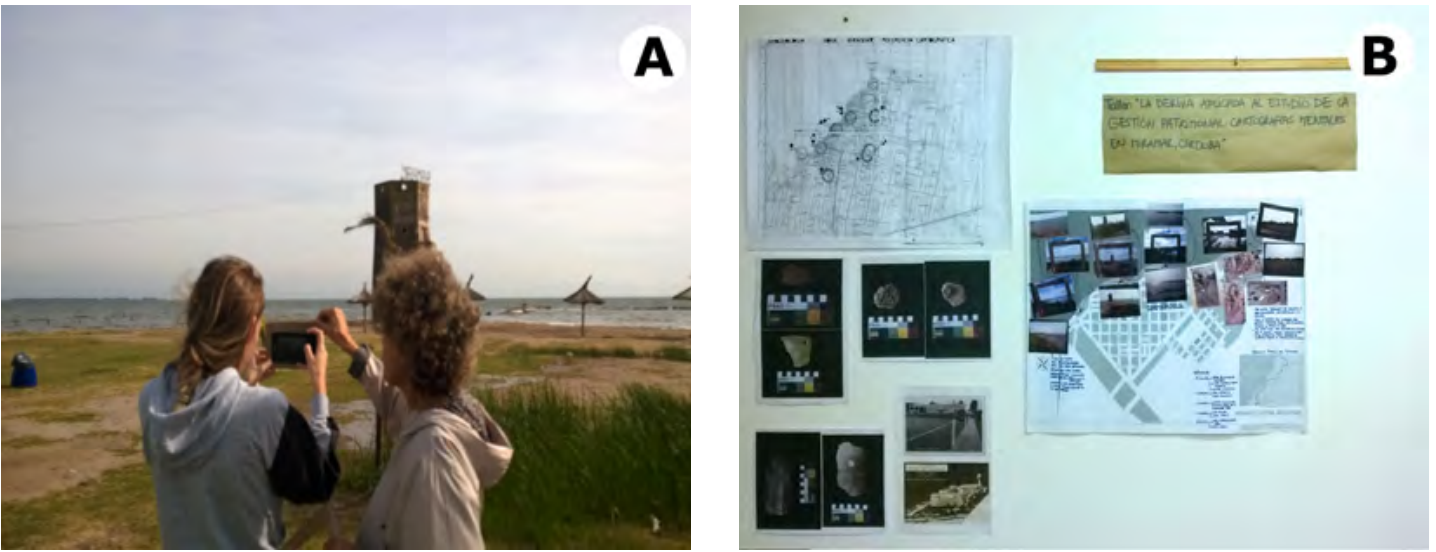

aguas, situación que se prolonga por toda la costa sur de la gran laguna de Mar Chiquita. Las participantes recalcaron: "Todos los lugares que recorrimos poseen valor patrimonial porque acá está nuestra historia. Porque conociendo nuestro pasado integramos (valoramos) el presente y nos proyectamos a futuro con conocimiento de lo que vivimos" (E. A. Bianciotti, comunicación personal, 6 de mayo de 2017). Además, el tema del turismo natural volvió a surgir, ya que desean "que el turista conozca y valore el lugar".

FIGURA 6.

Taller "La Deriva aplicada al estudio de la gestión patrimonial: cartografías mentales en Miramar (Córdoba)": a. Participantes del taller; b. Mapa de los paisajes arquetípicos de Miramar y material de apoyo Fuente: Elaboración propia.

Un pilar importante dentro de la metodología de trabajo fue generar reflexiones sobre la práctica y los saberes co-construidos. Este análisis fue posible gracias a dos elementos: los documentos formales propios de cada taller (planificaciones, insumos y materiales metodológicos producto del trabajo realizado, y registro mediado por la observación participante) y las evaluaciones por parte de los participantes de los talleres (diana de evaluación y ficha de evaluación). En cuanto al primer elemento, convirtió simultáneamente a todos los que asistimos en observadores y participantes de los talleres, con lo cual se asumen dos roles indisociables en el trabajo de campo de tipo etnográfico, ya que:

Con su tensión que es inherente, la observación participante permite recordar, en todo momento, que se participa para observar y que se observa para participar; esto es, que involucramiento e investiga- 
ción no son opuestos sino partes de un mismo proceso de conocimiento social (Holy, 1984).

Las instancias de evaluación estuvieron presentes en todos los talleres a través de la diana de evaluación, que es un sistema de evaluación participativa inmediato y muy visual (Díaz Escalera, 2012). Se evaluaron cuatro aspectos: metodología (equilibrio de teoría y práctica), ambiente de participación, aplicación práctica de los contenidos abordados y valoración general (ver Figura 7a). Para nosotros fue muy importante esta instancia porque los talleres siempre fueron pensados desde la reflexividad, en donde los participantes y los facilitadores co-construyen aprendizajes y contenidos a lo largo de las cinco sesiones que conformaron el ciclo, ya que las metodologías y las técnicas de la investigación participativa requieren de una reinterpretación permanente, que permita ajustar las prácticas a las coyunturas y particularidades de cada proceso de investigación.

Por último, desarrollamos una sesión de devolución: “¿Por qué dijimos lo que dijimos?”, en donde se expusieron todos los mapas creados en los diferentes talleres. Esta última actividad se plan- teó como un espacio fundamental de devolución y diálogo con la comunidad, en el entendimiento de que, como investigadores sociales, debemos generar espacios que potencien y fomenten el acceso de la ciudadanía a su patrimonio cultural y a los estudios que devienen del mismo (ver Figura 7b). Esta actividad finalizó con una ficha de evaluación en la que pretendimos plasmar y sistematizar la experiencia (positiva o negativa) de la comunidad con el ciclo de talleres. Evaluamos cinco criterios: 1) claridad con la que se abordaron las temáticas, 2) distribución y uso del tiempo, 3) instancias de participación y debate, 4) utilidad práctica de los temas discutidos y 5) si la actividad posibilitó reflexionar sobre el patrimonio de Miramar. El sistema de valoración se basaba en una escala de $0-2$, donde 0 era totalmente en desacuerdo, 1 parcialmente de acuerdo y 2 totalmente de acuerdo. Como este taller no tuvo un gran número de asistentes (3 participantes), se acercó la ficha a los participantes de los talleres anteriores que no pudieron asistir a la sesión de devolución. En líneas generales, visualizamos una aceptación positiva de las actividades y el deseo de repetir ese tipo de talleres participativos.

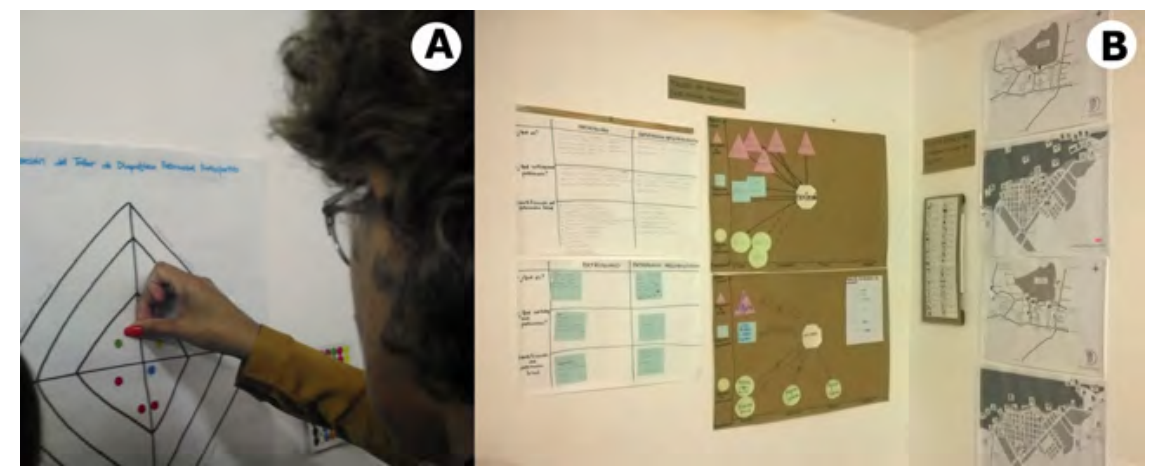

FIGURA 7.

Instancias de evaluación de los talleres: a. Diana de evaluación del taller Diagnóstico Patrimonial Participativo; b. Sesión de devolución: socialización de la cartografía generada en los talleres Diagnóstico Patrimonial Participativo (izquierda) y Mapeando al Paso (derecha) Fuente: Elaboración propia 


\section{Reflexiones sobre el}

\section{hacer cartográfico y algunas}

\section{conclusiones}

Los mapas, como productos del proceso cartográfico, fueron pensados como un medio y no como un fin, ya que entendemos que los mapas no son el territorio (Ares \& Risler, 2013), sino una imagen estática de un momento y un contexto sociocultural determinado. El mapa no es una imagen exacta de la realidad (Harley, 1989; 1991), sino una "fotografia" parcial del territorio, un relato dinámico que, siempre estará incompleto aunque se haya finalizado (Diez Tetamanti \& Rocha, 2016). Entendemos el mapa como "una representación gráfica de un espacio físico y social, resultado de trayectorias subjetivas y comunitarias de los participantes", por lo que los mapas no son representaciones espaciales neutrales, libres de los valores del mundo, sino que están cargados y condicionados por sus creadores. Pero que sean construcciones sociales no implica que carezcan de legitimidad, al contrario, "su riqueza consiste en reflejar las visiones y dinámicas de una comunidad en un espacio dado" (Vélez Torres et al., 2012, p. 68).

Al asumir esa carga ideológica y de poder que conllevan intrínsecamente los mapas, en nuestro proceso cartográfico participativo intentamos alejarnos de reproducir relaciones desiguales de poder, en el sentido de no querer imponernos desde nuestro posicionamiento académico y externo a la localidad y, por el contrario, tener siempre presente que como investigadores somos sujeto y objeto con fronteras difusas, pero que nuestro rol dentro del método cartográfico siempre debía ser solo el de facilitadores del proceso de construcción colectiva. Por eso, en el proceso cartográfico adquirió un rol de centralidad la participación comunal a través de sus experiencias, ya que desde la CS el reconocimiento y el análisis del espacio geográfico son resultado de varias etapas de participación, debate y discusión.

Al mismo tiempo, se procuró evitar sesgos en los grupos que se conformaron en los talleres, ya que, como plantean Sletto et al. (2013), los procesos de mapeo participativo tienden a estar dominados en su mayoría por hombres de la comunidad que son, a su vez, los que tienen mayor acceso a los espacios de toma de decisiones, lo cual genera la exclusión de las mujeres y de los jóvenes de los proyectos. Para ello se alentó la participación de todos los colectivos que constituyen la comunidad, especialmente el colectivo femenino, y se logró, así como con niños y jóvenes. Para lograr esto fue clave la difusión previa de los talleres en distintos espacios sociales y culturales de la ciudad (Técnica de Turismo, Escuela Primaria Jerónimo Luis de Cabrera, museos, Centro de Jubilados, radios locales, Municipalidad, Cooperativa Eléctrica, supermercado y comercios locales), así como el boca a boca, para invitar un público muy variado y lograr una alta participación femenina (un 70\% en la totalidad del ciclo de talleres).

Otro aspecto que se tuvo en cuenta fue la propuesta conceptual de la gestión integral del patrimonio, que entiende que el patrimonio arqueológico solo puede ser comprendido en su contexto territorial, junto con los otros patrimonios que forman un territorio (patrimonio mueble, patrimonio inmaterial, patrimonio natural, patrimonio construido, etc.), en una suerte de integración multipatrimonial. Por eso si bien nuestro principal objeto de análisis fue el patrimonio arqueológico local, en el transcurso de las actividades surgieron estos otros 
patrimonios, en particular el patrimonio natural representado por la gran laguna de Mar Chiquita, que es muy valioso para los miramarenses. Entonces fue importante no restringir las miradas a un solo patrimonio, sino dejar que se dialogara sobre todos los patrimonios con los que se identificaban, lo que nos permitió una visión más transversal de las construcciones en torno al patrimonio cultural de Miramar. También se tuvo presente que la CS como propuesta teórica-metodológica, particularmente para los estudios de gestión patrimonial, es un campo de indagación con un recorrido incipiente, de poco más de una década, y que debe seguir configurando tanto su corpus teórico como sus prácticas para fortalecer sus procedimientos, fundamentos y posibilidades.

Con nuestro trabajo de campo pudimos comprobar que el empleo de diferentes mapeos fue esencial para generar una perspectiva ampliada y procesual de las problemáticas abordadas, en tanto que es muy difícil poblar en un solo mapa todas las relaciones o temas que configuran el territorio y el centrarnos en una sola técnica nos llevaría a fragmentar más esa realidad territorial. Los mapas surgidos del ciclo de talleres de CS ofrecieron una alternativa para que las comunidades puedan construir un diagnóstico territorial de la vivencia comunitaria. El taller de Diagnóstico Participativo Patrimonial permitió empezar a visibilizar los agentes locales, a la vez que se generaron grupos de reflexión y discusión en relación con el patrimonio local. Por su parte, en el taller de Mapeo al Paso se crearon dos mapas muy distintos y el realizado por los lugareños expuso y visibilizó problemas locales en torno a la gestión de los patrimonios locales. Por último, con la Deriva se consiguió redescubrir el territorio y acercar ese patrimonio arqueológico oculto, y en algunos casos perdido por la subida de los niveles de la laguna, que ha ocasionado que varios sitios arqueológicos actualmente se encuentren bajo las aguas, situación que se prolonga por toda la costa sur de la gran laguna de Mar Chiquita.

Al mismo tiempo, a través de los mapeos fueron resurgiendo memorias y significados siempre arraigados a la laguna, que si bien hoy en Miramar se potencia principalmente como recurso turístico, para los miramarenses es mucho más que eso. Ella guarda el recuerdo de lo perdido, lo que no se ve, pero que siempre está presente en el imaginario de quienes allí viven. En relación con el patrimonio arqueológico, en la mayoría de los mapas creados se encontraba invisibilizado, aunque tuvimos constancia por las entrevistas y las charlas informales de que los miramarenses tenían conocimiento de los vestigios hallados en la localidad y los alrededores. El patrimonio histórico reciente tuvo más peso en las representaciones patrimoniales plasmadas en los mapas. Otro asunto que incidió en este aspecto es que los materiales recuperados en Miramar se encuentran albergados en el MCNAM, pero la mayoría de ellos no se exhiben por problemas de espacio. Por eso es un patrimonio que no se encuentra tan presente, sin embargo, en el recorrido de la Deriva, cuando a través del material de apoyo se mostraron fotos de algunas piezas arqueológicas halladas, estas suscitaron curiosidad y deseos en las participantes de poder tener, en un futuro, un mejor acceso a estas.

Sumado a esto, a partir de los mapeos realizados se pudo vislumbrar que la resiliencia es la característica con la que podemos definir a los miramarenses, una comunidad que se ha erigido una y otra vez, siempre desde el apego y con un respeto singular por la laguna, ya que no conciben Miramar sin ella y forma parte indisoluble de la percepción 
de su paisaje cultural. Esto quedó plasmado a lo largo de los talleres realizados, por ejemplo, en el Diagnóstico Patrimonial Participativo, cuando se preguntó sobre qué identificaban como patrimonio local, la laguna estuvo presente como elemento patrimonial en los dos grupos. En el caso de los participantes del grupo 1 de este taller, cuando se les preguntó qué consideraban como patrimonio, expresaron: "Lugares físicos, naturales, que nos identifican, que hacen parte de la historia y que debemos conocer para transmitir".

A su vez, si bien esta metodología ayudó a empoderar a los participantes, es importante destacar que al principio fue difícil generar espacios en donde la gente se sintiera cómoda y con las herramientas necesarias para involucrarse en el mapa. La complejidad de ciertas técnicas dificulta la total implicación de los participantes que no estén familiarizados con esta metodología y eso implica también un proceso de autodescubrimiento por parte de ellos, para que se reconozcan como agentes válidos para generar conocimiento y liberar voces no escuchadas previamente. En algunas actividades como el taller de Mapeo al Paso, por ejemplo, muchas personas no creían que tuvieran algo para decir o compartir, por eso nosotros, como facilitadores del proceso, debimos generar un ambiente de confianza para evitar estas situaciones y abrir vías de diálogo horizontales con los participantes. Este aspecto fue clave durante los mapeos realizados, ya que permitió que los participantes pudieran transmitir, sin sentirse coaccionados, sus visiones y opiniones sobre la situación actual que está atravesando la localidad en relación con el creciente turismo o la próxima declaración de parque nacional.

De este modo, por medio de la CS se pretendió em- poderar a la comunidad sobre las potencialidades y amenazas naturales de su territorio ante proyectos que puedan implicar un cambio profundo en el espacio habitado. A través de los mapas creados tendimos puentes para abrir nuevos mecanismos de participación ciudadana en temas relativos a la planificación del territorio y la gestión patrimonial, permitiendo así a la comunidad lograr una mayor autonomía e incidencia para participar en futuros procesos de desarrollo que se implementen en su territorio, ya que en los talleres se hizo hincapié de la falta de políticas y sobre todo de recursos económicos para implementar una gestión patrimonial desde metodologías participativas. Toda esta situación provoca falta de motivación y compromiso en la sociedad en general a causa de la escasa promoción de estas políticas desde el ámbito de las instituciones locales. Como se expresó en el taller de cartografía comunitaria: "A lo mejor no es solo la falta de interés, sino que al no haber promoción y capacitaciones las personas no participan", y existe "falta de incentivo para que trabajemos comunitariamente" (participantes del grupo 1).

Finalmente, a través de esta experiencia pudimos vislumbrar la utilidad social que tiene el saber cartográfico local como herramienta de enunciación, sistematización y reflexión sobre el territorio local, que permite conocer la realidad territorial a partir de las narrativas comunitarias y reafirma la pertenencia a un territorio. Pero resulta esencial que estos saberes no solo se queden en un plano de análisis académico, sino que puedan tener una real incidencia en otras esferas sociales y políticas, abriendo caminos a otras (re)apropiaciones del territorio y nuevas políticas públicas de gestión patrimonial desde una visión integral. En este contexto surgió la propuesta de Mirapedia, una enciclopedia participativa, que se basa en el recurso 
wiki, sobre los patrimonios de Miramar (Córdoba, Argentina), que busca la creación de espacios de apropiación colectiva del conocimiento local para ofrecer versiones alternativas a los discursos dominantes desde una cartografía participativa (Martin Silva, 2017). Este proyecto fue presentado en la Escuela Primaria Jerónimo Luis de Cabrera y en el MCNAM, y ha tenido apoyo y una aceptación positiva por parte de la comunidad local ${ }^{13}$.

Es por eso por lo que, con el trabajo llevado a cabo y las propuestas que se encuentran todavía en vía de desarrollo (como Mirapedia), se pretendió contribuir a la puesta en valor del territorio, tanto de los espacios naturales como de los culturales, que sirva para la toma de conciencia ciudadana y para visibilizar la propia evolución histórica del territorio de Miramar de Ansenuza y sus patrimonios

13 La propuesta de Mirapedia suscitó mucha curiosidad, a tal punto que fuimos invitados a dar una charla sobre el uso de las wikis en la construcción del conocimiento en el Instituto Superior de Formación Docente Santa Teresita en Balnearia, localidad ubicada a $12 \mathrm{~km}$ al sur de Miramar de Ansenuza. desde las miradas de los miramarenses. Así, el mapeo colectivo se presenta como el medio alternativo para la puesta en valor, la activación y la recuperación de los bienes comunes existentes en el territorio.

\section{Agradecimientos}

Agradecemos a los guías Hugo Giraudo y Anabela Kaffer, y al presidente de la Asociación de Amigos del Museo de la Región de Ansenuza “Aníbal Montes", Juan José Scienza, por la ayuda brindada durante nuestro trabajo de campo. Un especial agradecimiento a Julieta Bellis, integrante del Programa de Arqueología Pública (UNC) por la colaboración en el desarrollo de algunos de los talleres de mapeo colectivo. Por último, agradecemos a todos los miramarenses que tuvieron la predisposición de compartir sus saberes sobre los patrimonios de Miramar. 


\section{Referencias}

Acosta Bono, G. (2011). Cartografía y patrimonio en perspectiva. Revista PH, 77, 4-11.

Aichino, G. L., De Carli, M. C., Zabala, M. E. \& Fabra, M. (2012). Procesos de activación y valoración del patrimonio arqueológico a través de la Cartografía Social. Revista EXT, 3,1-27.

Aichino, G. L., de Carli M. C., Zabala M. E. \& Fabra. M. (2013). Mapeando el Patrimonio Arqueológico de Córdoba. Propuesta educativa para el nivel medio con orientación en Ciencias Sociales y Humanidades. Colección Cuadernos de Trabajo. Propuestas para la integración progresiva de saberes en la escuela secundaria. Recuperado de https://ansenuza.unc.edu.ar/comunidades/handle/11086.1/761

Almeida, A. (2013). Nova cartografia social da Amazônia. En A. Almeida (org.), Nova Cartografia Social da Amazonia. Povos e comunidades tradicionais. Catálogo, livros, mapas, fascículos, simpósios, vídeos (pp. 29-34). Manaus: UEA.

Anderson, B. (1991). Comunidades imaginadas. Reflexiones sobre el origen y la difusión del nacionalismo. México: Fondo de Cultura Económica.

Andrade, H. (2001). La cartografía social para la planeación participativa: experiencias de planeación con grupos étnicos en Colombia. Caracas: Centro Latinoamericano de Administración para el Desarrollo.

Andrade, H. \& Santamaría, G. (2010). Cartografía social: el mapa como instrumento y metodología de la planeación participativa. En Memorias del curso Participación Comunitaria y Medio Ambiente. Proyecto de capacitación para profesiones del Sector Ambiental. Bogotá: Ministerio del Medio Ambiente e ICFES.

Ares, J. \& Risler, P. (2013). Manual de mapeo colectivo: recursos cartográficos críticos para procesos territoriales de creación colaborativa. Buenos Aires, Argentina: Tinta Limón.

Azócar, P. (2017). Un análisis epistemológico desde la cartografía postmoderna y su relación con la segunda filosofía de Wittgenstein. Cinta de Moebio. Revista de Epistemología de Ciencias Sociales, 59, 129-142. doi: 10.4067/S0717$554 \times 2017000200129$.

Ballesteros Arias, P., Otero Vilariño, C. \& Varela Pousa, R. (2005). Los paisajes culturales desde la arqueología: propuestas para su evaluación, caracterización y puesta en valor. ArqueoWeb, Revista sobre Arqueología en Internet, 7(2), 1-13.

Barroso Hoffman, M. (2010). Mapeamentos participativos e atores transnacionais: a formação de identidades políticas para além do Estado e dos grupos étnicos. En H. Acselrad (coord.), Cartografia social e dinámicas territoriais: marcos para o debate (pp. 47-80). Río de Janeiro: IPPUR, UFRJ.

Blasco, J., Lamas, G., Gentile, B., Villarmarzo, E. \& Gianotti, C. (2014). Aprendiendo de nuestras prácticas. Sistematización del proyecto Cartografiando patrimonios. Cartografía social en Laguna de Rocha. En L. Berutti, M. Cabo y M. J. Dabezies (eds.), Apuntes para la acción III. Sistematización de experiencias de extensión universitaria. Montevideo, Uruguay: Universidad de la República, CSEAM. 
Bucher, E. H., Coria, R. D., Curto, E. D. \& Lima, L. L. (2006). Conservación y uso sustentable. En E. H. Bucher (ed.), Bañados del río Dulce y laguna Mar Chiquita (Córdoba, Argentina) (pp. 327-341). Córdoba, Argentina: Academia Nacional de Ciencias.

Carballeda, A. J. M. (2012). Cartografías e Intervención en lo social. En J. M. Diez Tetamanti y B. Escudero (comp.), Investigación e intervención desde las ciencias sociales, métodos y experiencias de aplicación (pp. 20-36). Comodoro Rivadavia, Argentina: Universidad de la Patagonia.

Castro Jaramillo, M. L. (2016). Cartografía Social como recurso metodológico en los procesos de planeación participativa de un territorio incluyente. El caso del Plan Parcial de Renovación Urbana “El Triángulo de Fenicia” en la ciudad de Bogotá. (Trabajo de grado). Facultad de Arquitectura y Diseño, Pontificia Universidad Javeriana, Bogotá, Colombia.

Consejo Internacional de Monumentos y Sitios Culturales (Icomos). (1990). Carta Internacional para la Gestión del Patrimonio Arqueológico. Preparada por el Comité Internacional para la Gestión del Patrimonio Arqueológico (ICAHM) y adoptada por la Asamblea General del Icomos en Lausana en 1990.

Crampton, J. W. (2001). Maps as social constructions: power, communication and visualization. Progress in Human Geography, 25(2), 235-252.

Díaz Escalera, M. (2012). La diana, evaluación participativa. Recuperado de https:// es.slideshare.net/fqmanuel/evaluacin-participativa-la-diana

Diez Tetamanti, J. M. (2012). Cartografía social. Herramienta de intervención e investigación social compleja. El vertebramiento inercial como proceso mapeado. En J. M. Diez Tetamanti y B. Escudero (comp.), Investigación e intervención desde las ciencias sociales, métodos y experiencias de aplicación (pp. 13-24). Comodoro Rivadavia, Argentina: Universidad de la Patagonia.

Diez Tetamanti, J. M. \& Rocha, E. (2016). Cartografía aplicada a la intervención social en el Barrio Duna, Pelotas, Brasil. Revista Geográfica de América Central, 2(57), 97-128.

Dodge, M., Kitchin, R. \& Perkins, C. (2009). Rethinking Maps New Frontiers in Cartographic Theory. London: Routledge Studies in Human Geography.

Fabra M., Roura Galtés, I. \& Zabala, M. (2008). Reconocer, recuperar, proteger, valorar: prácticas de arqueología publica en Córdoba. En A. M. Rocchietti \& V. Pernicone (comp.), Arqueología y educación: perspectivas contemporáneas (pp. 117-132). Buenos Aires, Argentina: Tercero en Discordia.

Fabra, M. \& Zabala, M. E. (2015). Humanidad, patrimonio, ancestros: ¿de qué hablamos cuando hablamos de arqueología pública en Córdoba? En M. Fabra, M. Montenegro \& M. E. Zabala (eds.), La arqueología pública en Argentina: historias, tendencias y desafíos en la construcción de un campo disciplinar (pp.53-75). Jujuy, Argentina: Universidad Nacional de Jujuy.

Ganter, R., Sandoval, D., García D. \& De la Fuente, H. (2015). Topofilia y cartografías participativas en el sur de Chile. La experiencia comparada en las ciudades de Temuco-Padre las Casas, Valdivia y el Gran Concepción. Prisma Social, 15, 440-491. 
García, C. (2005). Proyecto "Barrios del Mundo: Historias Urbanas". La cartografía social en la práctica. ENDA Colombia.

Geertz, C. (2003 [1973]). La interpretación de las culturas. Barcelona, España: Gedisa.

Habegger, S. \& Mancila, L. (2005). La cartografía social como estrategia para diagnosticar nuestro territorio. En B. Celada \& S. Habegger (coord.), Interpretando a Freire. Haciendo camino desde la colectividad. Seminario de Paulo Freire (pp.29-36). Málaga, España: Colectivo Sur Ediciones.

Harley, B. (1989). Deconstructing the Map. Cartographica, 26(2), 1-20.

Harley, B. (1991). Cartography, Ethics and Social Theory. Cartographica, 27(2), 1-23.

Holy, L. (1984). Teoría, metodología y proceso de investigación. En R. Ellen (comp.), Ethnographic research: a guide to general conduct (pp. 13-34). London: Academic Press.

Instituto Nacional de Estadística y Censos de la República Argentina (Indec). (2010). Censo Argentino de 2010. Recuperado de https://www.indec.gov.ar/

Jiménez, A., Vela, M., Ramírez, J. M. \& García, P. (2013). Manual de metodologías participativas para iniciativas agroecológicas. Jerez de la Frontera, España: Ediciones Ecoherentes.

Ladrón de Guevara González, B., Toro Balbontín, D., Prieto Véliz, R. \& Chávez Valdivia, C. (2015). Patrimonio, territorio y paisaje: huellas del aprendizaje a ocho años de la creación de la Unidad de Geoinformación del Patrimonio. Conserva, 20, 123130.

Leiva, M. (2014). Situación de la producción de nutrias en Miramar - Córdoba. Córdoba, Argentina: Ediciones INTA, Estación Experimental Agropecuaria Manfredi.

Martin Silva, V. B. (2016). Nuevos sentidos en torno a la gestión patrimonial. PH: Boletín del Instituto Andaluz del Patrimonio Histórico, 90, 208-209. doi: $10.33349 / 2016.0 .3801$

Martin Silva, V. B. (2017). Mirapedia, un proyecto wiki como herramienta de colaboración y participación ciudadana en el noreste de Córdoba (Argentina). En C. Marta-Lazo (ed.), Perspectivas de la calidad informativa en la sociedad digital: antecedentes, estado actual y prospectiva (p. 102). Sevilla, España: Egregius Ediciones.

Martins, A. B. S. P \& Baeta Leal, C. F. (2015). Mapas e patrimônio: a cartografia na identificação do patrimônio cultural. Revista Geografía e Pesquisa, Ourinhos, 9(2), 29-36.

Mignolo, W. (2011). Historias locales/diseños globales. Colonialidad, conocimientos subalternos y pensamiento fronterizo. Sevilla, España: Akal.

Miramar ahora se llama Miramar de Ansenuza. (9 de julio de 2014). La Voz. Recuperado de http://www.lavoz.com.ar/regionales/miramar-ahora-se-Ilamamiramar-de-ansenuza-0 
Miramar: Concejo aprobó el cambio de nombre a la localidad. (8 de julio de 2014). Cooptel / Canal 50. Recuperado de https://www.cooptel.com.ar/noticia/miramarconcejo-aprobo-el-cambio-de-nombre-a-la-localidad-2692

Montoya Arango, V. (2007). El mapa de lo invisible. Silencios y gramática del poder en la cartografía. Universitas Humanística, 63, 155-179.

Montoya Arango, V., García Sánchez, A. \& Ospina Mesa, C. (2014). Andar dibujando y dibujar andando: cartografía social y producción colectiva de conocimientos. Nómadas, 40, 190-206.

Paez i Blanch, R. (2014). Derivas urbanas: la ciudad extrañada. Rita: Revista Indexada de Textos Académicos, 1, 120-129.

Patiño Jiménez, O. A. (2014). La cartografía social como método para la enseñanza del territorio en la geografía, en zonas de influencia de megaproyectos, caso: Túnel AburráOriente, Antioquia-Colombia, Escuela Guillermo Gaviria Correa, vereda Yarumal, 20142015. Recuperado de http://observatoriogeograficoamericalatina.org.mx/egal15/ Nuevastecnologias/Cartografiatematica/07.pdf

Piovano, L. E, Ariztegui, D., Córdoba, F., Cioccale, M. \& Sylvestre, F. (2009). Hydrological variability in South America below the tropic of Capricorn (Pampas and Patagonia, Argentina) during the last 13.0 ka. En F. Vimeux, F. Sylvestre y M. Khodri (eds.), Past climate variability in South America and surrounding regions (pp. 323-351). Dordrecht, The Netherlands: Springer, Developments in Paleoenvironmental Research Series.

Prats, L. (1997). Antropología y patrimonio. Barcelona: Ariel.

Salamanca, C. (2012). Memoria, acción colectiva y narrativas territoriales: paradojas y desafíos de la cartografía social en Argentina. En C. Salamanca \& R. Espina (coord.), Mapas y derechos. Experiencias y aprendizajes en América Latina (pp. 141 194). Rosario: Universidad Nacional de Rosario.

Sletto, B. (2010.) Autogestión en representaciones espaciales indígenas y el rol de la capacitación y concientización: el caso del Proyecto Etnocartográfico Inna Kowantok, Sector 5 Pemón (Kavanayén-Mapauri), La Gran Sabana. Antropológica, 53(113), 43-75.

Sletto, B., Bryan, J., Torrado, M., Haley, C. \& Barry, D. (2013). Territorialidad, mapeo participativo y política sobre los recursos naturales: la experiencia de América Latina. Cuadernos de Geografía: Revista Colombiana de Geografía, 22(2), 193-209.

Vélez Torres, I. V., Rátiva Gaona, S \& Varela Corredor, D. (2012). Cartografía social como metodología participativa y colaborativa de investigación en el territorio afrodescendiente de la cuenca alta del río Cauca. Cuadernos de Geografía: Revista Colombina de Geografía, 21(2), 59-73.

Viladevall, M. (Comp.). (2003). Gestión del patrimonio cultural: realidades y retos. México: BUA.

Zabala, M. E \& Fabra, M. (2012). Estrechando vínculos entre "comunidades" en torno al patrimonio arqueológico. Las prácticas extensionistas desde un programa de Arqueología Pública. Revista de Arqueología Pública, 6, 39-54. 
Zabala, M. E., Fabra, M., Aichino, G. L. \& de Carli, M. C. (2015). Patrimonial Education and Cultural Rights: The Contribution of Archaeological Heritage to the Construction of Collective Memories. Public Archaeology, 14(1), 27-43.

Zabala, M. E., Fabra, M., Aichino, G. L. \& de Carli, M. C. (2016). Reflexiones en torno a los aportes que realiza la Arqueología Pública en la construcción de memorias e identidades locales en el NE de la provincia de Córdoba (Argentina)", E+E Revista de Extensión en Humanidades, 4(4), 8-22.

Zapata, M. (2011). Historias que dejaron huellas. Córdoba, Argentina: Impresiones BC. 